\title{
Implementing and Sustaining Educational Change and ICT: A Case Study of a Taiwanese Primary School
}

\author{
Yih-Shyuan Chen and Ian Selwood \\ The University of Birmingham, UK \\ katycys@gmail.com, I.D.Selwood@bham.ac.uk
}

\begin{abstract}
This paper is a case study of a school in Taiwan. The School in this study has successfully implemented and sustained the integration of ICT across the curriculum to support teaching and learning, whilst other similar schools have failed to maintain the impetus of a national project. By using questionnaires, interviews and document analysis the leadership and management, organisational processes and decision-making, and ICT resources and technological adoption were analysed. The study highlights the importance of shared, collaborative leadership in implementing and sustaining the integrating of ICT into teaching and learning.
\end{abstract}

Keywords: ICT, educational change, leadership, teacher attitudes.

\section{Introduction}

The introduction and/or extension of the use of Information and Communications Technologies (ICT) in school settings has been of concern for some time, as is evidenced by studies of change management and ICT integration in school settings [10, $12,14]$. The significance and importance of ICT in education is widely acknowledged. Nevertheless, research has often highlighted barriers to ICT implementation in schools [5]. Studies by Kennewell et al. [6] and Tearle [14] examined factors which underpin successful ICT implementation in schools in the UK, identifying the key attributes of the ICT-capable schools: the headteacher's and senior managers' strong lead and active involvement in ICT development, collegiate work patterns amongst the staff, convenient access to ICT resources and support, and adequate staff ICT training. The above attributes were also verified by Sheppard [12] and Wong and Li [16] to be crucial for whole-school change and ICT integration in other educational contexts, including Canada and Hong Kong. Yet these researchers went further, concluding that shared leadership tended to be a radical driver for a collaborative culture which had a potential impact on sustaining school improvement in ICT development. Indeed in his studies, Selwood noted that the role of school leadership and management, particularly the headteacher's leading style, was the core of success in the widespread use of ICT in schools [11].

The ICT Seed School Project (ICT SSP) was a national ICT-related project announced by the Taiwanese Ministry of Education in 2002, that aimed to extend the 
use of new technologies in schools by integrating ICT into the curriculum. These ICT Seed Schools were given training and financial support to expand their use of ICT across the curriculum. They were then expected to support other schools with their ICT development. Some schools in the ICT SSP were very successful in implementing and sustaining the project, others less so.

Given the above context, the aim of the present research is to explore the effect of school leadership and management on educational change for ICT development. Centring on a specific rural primary school in Taiwan, this study examined the way in which the entire staff succeeded in transforming a traditional school with limited technological resources into an acknowledged ICT-capable school. Thus, the findings can possibly show the patterns of change management concerning ICT development in Taiwanese rural schools.

\section{Theoretical Framework}

The theoretical framework of this study was built on two areas of literature. The first of these concerns school change and improvement, with a focus on the issues of school leadership and management. Leithwood [7] examined the features of effective school management in various countries and identified three common principles of successful leadership practices: 'setting directions' - the development of a shared vision, consensus about school targets and high performance expectations for staff work; 'developing people' - enhancing teachers' individualised and professional support, staff commitment, and important values for school development; 'redesigning the organisation' includes shaping a collaborative learning culture, motivating staff to participate in decision-making, and building the relationships with parents and the community.

The other area of work that influenced the design of this research was school staff's responses to the introduction of new technologies in teaching practices. These intention-based theories are essential in bringing about an understanding of and an ability to predict individuals' attitudes and reactions when new technologies intervene in school contexts [8, 13]. Therefore, the literature concerning intention-behaviour models, such as the Theory of Planned Behaviour constructed by Ajzen [1] and the studies of individuals' acceptance of ICT adoption [2, 13], were used in this research to explore teachers' reactions to ICT adoption.

\section{Methodology}

A case study approach is used in this research and as such the evidence used covers many sources, since multiple information is highly complementary [17]. Questionnaires, semi-structured interviews and document analyses were used for gathering both quantitative and qualitative data from the case study school. Purposeful sampling was applied to ensure the school selected for this study was an information-rich site in which the ICT Seed School Project (ICT SSP) was continuing at the time of the research. 
The school selected for this research was a rural primary school in Taiwan and had 21 classes, with 578 pupils on roll, and 30 teaching staff plus the headteacher. Prior to being involved in the ICT SSP the target school was short of technological resources. However, it has become publicly acknowledged as an ICT-capable school and officially recognised by the Ministry of Education as a model for other schools, and its experiences in change management for ICT disseminated around many schools in Taiwan. In addition the school also provides training sessions in the use of ICT for parents and teachers from other schools. Furthermore, to confirm the school's status as a high achieving school the researchers carried out a measure of its "ICT maturity" using the tool developed by Underwood and Dillon [15] and the school showed a high level of ICT maturity.

Questionnaires were distributed to 28 school staff and responses were received from $25(89 \%)$. Following an initial analysis of the data 22 members of staff were interviewed: 10 were from the ICT instructional team ${ }^{1}, 6$ were teachers from outside this team, and another 6 were seen as key personnel (the ex- and current headteachers, ex- and current directors of academic affairs, the ICT coordinator and an ex-teacher). All the interviews were recorded and then transcribed. Data was also collected by analysing official school documents such as development plans, school policies and minutes of meetings.

\section{Findings}

The findings from this research were obtained by examining the staff's opinions on the following issues: leadership and management, organisational processes and decision-making, and ICT resources and technological adoption.

\subsection{Leadership and Management}

The research data showed that a large proportion of respondents (97\% from the questionnaires and $100 \%$ from the interviews) were positive about the leadership and management approaches to ICT development in the school. The leadership style was seen as collaborative and supportive by all respondents and $92 \%$ of the questionnaire respondents felt that the school's aims and direction were clear when undertaking educational change resulting from central government initiatives.

Supporting the data from the questionnaires, all teachers who were interviewed confirmed that the headteacher's strong leadership, together with a clear school vision and strong support for educational innovations, encouraged them to accept the need to implement ICT innovations. When asked about their opinions on the governmental action on educational shift, 16 interviewees (73\%) felt positively that change was essential for progress in all aspects of education. They also concluded that the staff generally welcomed educational change for school improvement and were prepared to take risks as part of the improvement process. For instance one teacher said:

\section{"Of course, making change cannot always guarantee the desirable outcomes."}

\footnotetext{
${ }^{1}$ The ICT instructional team was an ICT-focused learning community within the school whose members were the headteacher, departmental directors, ICT coordinator and classroom teachers.
} 
Delegation of responsibilities to the staff was also mentioned positively and repeatedly in the interviews. As the headteacher declared, he personally did not take a direct lead in ICT innovations in the school. Instead, it was his belief that delegating power to the teachers with ICT knowledge and great enthusiasm about school management was the way of strengthening their commitment to strive for excellence in ICT implementation. On this basis, he felt comfortable empowering the staff with ICT expertise to lead the school in making progress in implementing ICT. Indeed the headteacher contended that:

"Without the continuous and joint efforts of the ICT coordinator, director of academic affairs and classroom teachers in managing school-wide educational innovations, it would have been almost impossible for our school to launch and sustain ICT improvement."

The headteacher's firmly-held belief in shared leadership and management may explain why all interviewees attributed their present level of ICT implementation not only to the strong lead from the headteacher, but also to the exceptional competence of both the ICT coordinator and director of academic affairs in guiding the school through the difficulties in integrating ICT.

For the ICT coordinator and director of academic affairs, it was the headteacher's great trust in their abilities and that they were able to have a strong sense of freedom in managing whole-school ICT improvements. The ICT coordinator also maintained that:

"We all understand that our headteacher is not specialised in new technologies...[Yet] whenever the government's funding is not sufficient enough for us to upgrade our ICT equipment, he [the headteacher] is sure to make efforts to solve the "money problems"...This is really helpful...He encourages us, helping us overcome the growing pains in the course of managing the ICT SSP."

When explaining how staff collaborated in implementing ICT across the curriculum, $96 \%$ of the interviewees raised a common example as follows. In order to put the plan for ICT integration forward, the ICT coordinator and director of academic affairs invited classroom teachers, particularly those who were ICT competent, to constitute the ICT instructional team which offered instructional and technical assistance in meeting teachers' individualised demands for teaching with ICT.

Importantly, apart from the headteacher and other managers, teaching staff in the ICT instructional team were identified by many interviewees $(77 \%)$ as teacher pioneers in extending the use of ICT in the school. This is mainly because before the start of school-wide technological adoption, the ICT instructional team worked together with the ICT coordinator in developing and experimenting with different modes of ICT-integrated curricula in selected classes. These trials, associated with action research, enabled the ICT instructional team to share their experiences of ICT integration, including suggesting strategies for overcoming challenges, with other teachers in advance. As a result, most teachers came to realise the ways of preparing themselves for confronting the educational innovations in teaching practices. Given this context, it may be unsurprising that $76 \%$ of the respondents to the questionnaires reflected that the staff as a whole were always ready to engage in educational change, and that the 
processes of change management in the school were generally acceptable. It could be said that not only the formal leaders and managers (i.e. the headteacher and directors), but also teachers from the ICT instructional team were the core in permeating the ICT culture throughout the school.

However, it would appear that the ethos of collaborative leadership had been rooted in the school before the current headteacher took up his post. For instance, in the interview with the ex-headteacher, he asserted that all teachers could be good leaders in their specialised areas if they were given suitable opportunities. Like the current headteacher, the ex-headteacher had also enabled school staff to feel free to exercise leadership practices in the school. As all teachers in the interviews contended, before undertaking the ICT SSP, the staff were frequently involved and participated in planning and decision making. Moreover, $86 \%$ of the interviewees pointed out that before commencing the ICT SSP, regular staff workshops for sharing individuals' experiences and new knowledge had already served as a solid foundation for constructing a positive atmosphere for staff teamwork. The interviewees specifically said that their previous experiences in implementing and managing government initiatives had taught them that mutual support within the staff assisted in overcoming difficulties. Hence, the staff accepted working and learning together with their colleagues as a natural part of the approach to dealing with educational change.

Notably, sharing responsibilities in leadership and management seemed to be a commonplace in the school, rather than being restricted to the area of ICT implementation. As the interviewees highlighted, distributed leadership was not restricted to ICT developments but applied to all areas of the school.

\subsection{Organisational Processes and Decision-Making}

Staff views on organisational processes and decision-making in the school were found to be generally very positive. All respondents believed that the staff at all levels were involved in decision-making and vested with adequate decision-making power, and that each of them took a defined role and responsibility in the organisational processes. Open debates and reflective evaluations were regarded by most respondents $(96 \%)$ as the usual approach to assessing the overall organisational performance. An equally large number of respondents (96\%) felt that staff communication was effective, and that they were kept well informed in respect of executive decisions and school policies. A considerable number of respondents (92\%) recognised that sharing responsibilities and close collaboration between teachers and leaders/managers was commonplace, particularly when making school plans. The same proportion (92\%) confirmed that leaders consulted teachers about decisions which would affect the whole school.

Further information from the interviews reflected that $91 \%$ of the staff enjoyed being involved in the decision-making processes. Although many admitted that contentious issues sometimes resulted in conflicting tensions, the interviewees claimed that with the prompt mediation of the headteacher and other senior managers, the conflicts turned into the constructive discussions, and this allowed them to consider deeply the issues under discussion, and this facilitated shaping shared values and developing a consensus before decisions were made. 
One experienced teacher said:

“It doesn't matter which post you are holding, your voices are always respected. People in this school care about others' feelings and thoughts both at formal meetings and in informal discussion. Whilst it is inevitable that some proposed ideas incurred our criticism at the very start, we are still willing to try them out to see how they work for our school. This is how we do things here."

While an inexperienced teacher noted:

"This school is like a family and the morale is very high... It was really heart-warming that everyone here tried making me feel accepted."

\subsection{ICT Resources and Technological Adoption}

It is apparent that even with good leadership without technological equipment and technical support a school can not integrate ICT effectively. Thus staff were asked their opinions on these aspects. Responses to the questionnaire showed that staff believed - hardware matched their needs (100\%), software met their needs $(96 \%)$, technical support catered for their needs $(96 \%)$, ICT resources were useful for their teaching (92\%), application of ICT enhanced teaching effectiveness (92\%), and ICT resources were always accessible to the staff $(88 \%)$.

The questionnaire data revealed that generally speaking teachers were confident and competent users of ICT. All respondents showed their confidence in ICT adoption, claiming that they were competent users of ICT and that they applied ICT appropriately to support teaching and learning; $88 \%$ believed that ICT adoption reduced their workload, and the same percentage $(88 \%)$ felt that the staff had been trained in all aspects of ICT necessary for their teaching. More importantly, nearly all respondents $(96 \%)$ were satisfied with the long-term training for the ICT SSP.

As might be expected given teachers' positive responses to the questionnaire, the interview data reported the staff's high satisfaction with the access to ICT facilities and technical support in the school. The interviewees also stressed that the ICT training held in the school demonstrated the strategies for developing the ICT-integrated curriculum. Thus, staff members, including those who at the start of the ICT SSP had limited ICT skills, became clear about the ways and benefits of using new technologies in teaching and learning. More importantly, the ICT instructional team and the ICT coordinator conducted the regular audits of teachers' ICT skills and needs. Based on these audits, the school then provided differentiated training sessions to meet staff and school needs. In addition, knowledge sharing through staff meetings and informal discussions enabled teachers to understand the utility of ICT and procedures for integrating ICT. For the interviewees, formal ICT training and informal staff discussions were useful for improving understanding the concepts of ICT adoption into their teaching practices.

The questionnaire data revealed that sufficient equipment, timely technical support and suitable training sessions were the base for extending the use of ICT in the school. However, when, compared with the responses concerning leadership and organisation processes above, $94 \%$ of the teachers in the interviews rated the strong determination and high expectations of the headteacher and other senior managers in 
pursuing ICT improvement was most influential on their willingness to engage in instructional innovations with ICT. Interviewees also stressed the endeavours of the headteacher and other senior managers to lead the school in establishing good relationships with parents and the community so that this solid school-community connection facilitated the school obtaining financial support from parents and neighbouring colleges, particularly when technological resources were limited at the commencement of ICT implementation.

\section{Discussion}

Whilst generalisations are impossible from the results of one case study, interesting issues can emerge. With respect to school leadership and management, it was clear that the evidence reinforced the conclusions of recent studies that the supportive and proactive lead from the headteacher in educational change is critical for school-wide instructional innovations concerning ICT integration $[11,16]$. Furthermore, it is apparent that the headteacher's comprehension of the staff's quality (i.e. skills and interests), together with his good appointment of the competent teachers as leaders and managers (i.e. the ICT coordinator and departmental directors), seemed to be essential for success in planning and initiating whole-school ICT developments. Moreover, school leadership for innovations in ICT was not limited to managers and ICT experts at the implementation stage of ICT development. The leadership of a group containing classroom teachers (the ICT instructional team) helped the entire implementation of ICT by providing prompt feedback and solution of staff's individual problems.

The above findings reflect that leading and managing in the school was not the domain of any individual, but devolved across many members of staff. Furthermore, it appears that the headteacher's delegation of leadership to specific staff with vision and passion about ICT development, in the very early stages of implementing ICT, was critical for the effective commencement and continuity of whole-school ICT improvement. Such findings support the international multi-case studies by Leithwood [7], who affirmed teachers' participation in school leadership as an important foundation for successful change in nearly all educational contexts. The findings also support Sheppard's work, which reported that schools succeeding in developing ICT had participative or shared leadership but had at least one key person who acted as a leader and champion of school change for ICT implementation [12].

There is no doubt that staff collaboration in leadership and management is instrumental in school change. The evidence gathered here demonstrates that staff's collegial interaction and applying shared leadership to managing school improvements were formed through a long-term process, and were not confined to a particular domain, but permeated all aspects of school improvement. Similar results were also shown in Tearle's studies of effective school change for ICT development [14].

In addition, teachers in the school seemed to readily accept new ideas and educational change. The staff's awareness of the necessity for school change underpinned their intentions to keep improving in ICT implementation even when challenges occurred. Indeed the literature of educational improvement notes that school staff are typically willing to undertake change and development when feeling a critical need for doing so $[3,4]$. 
The findings related to organisational processes and decision-making made it evident that the school fostered high morale and a collaborative culture where collective plans and establishing a shared vision through open debates and reflective evaluations appeared to be deeply rooted in the staff working processes. This finding, that there is a strong link between shared leadership and a positive culture for school staff collaboration, has been well documented in other studies concerning successful ICT implementation $[12,14,16]$.

The headteacher and senior managers not only respected the divergence of individuals' opinions, but also assisted in moving wide-ranging debates forward to constructive dialogues for reaching common values amongst the staff. More specifically, even without formal management duties, some classroom teachers voluntarily managed and strengthened social networks of colleagues, and this was considered by the staff as instrumental for dealing with school-wide change. Again, these finings could correspond to Leithwood's assertion of the basic features of effective school management [7]. In his work, Leithwood claimed that successful headteachers have capacities for developing teacher consensus about the issues under discussion. On the other hand, they are competent in encouraging teachers to spontaneously engage in instructional innovations by means of reflecting upon existing practices critically, questioning taken-for-granted assumptions and participating in organisational processes.

With reference to staff views on ICT resources and technological adoption, the evidence showed the importance of sufficient ICT equipment and staff training cannot be over emphasised. Similar findings were also reported in other studies [11]. The approach of frequently auditing staff skills and needs and differentiated training based on this is worthy of note.

Furthermore, both formal ICT training and knowledge sharing amongst staff members in an informal manner facilitated teachers in perceiving the advantages of ICT integration and assimilation of new pedagogies regarding ICT into their teaching strategies. It could be summarised from these findings that the teachers were willing to deal with challenges caused by technological adoption, as long as they felt that using ICT for teaching and learning were compatible with their present instructional experiences and matched their needs. The studies by Chau and $\mathrm{Hu}$ [2], who explored organisational members' acceptance of technological adoption outside the educational field, also found that compatibility was the primary factor which determined whether individuals accepted or resisted the use of new technologies.

A particularly interesting issue which emerged in this study was that teachers' commitment to ICT development seemed to highly depend on the perceptions of their colleagues' resolution to improve schooling. Indeed, the interviews showed the teachers were conscious of the efforts of the school leaders (i.e. the headteacher, directors and ICT coordinator) and ICT instructional team to transform the school into an ICTcapable school, and this raised the entire staff's determination to launch and sustain ICT developments. Therefore, even though the school was limited in ICT resources at the very start of the development process, the teaching staff still had a strong will to work together in managing school improvement for ICT integration.

\section{Conclusion}

The school's achievement in implementing and sustaining its use of ICT was not simply the result of the headteacher's strong leadership, but the joint and intense engagement of 
staff members in leadership and management. Although the factors which affected ICT implementation in the school were inter-related rather than discrete, it was evident that collaborative leadership played the key role in underpinning school change for ICT implementation. Indeed, the finding of this study may be parallel to Morrison's argument that 'change concerns people more than content' (p. 15) [9]. Finally, as with work of Sheppard [12], this case study highlights the essential link between leadership and successful implementation of ICT in schools.

\section{References}

1. Ajzen, I.: From Intentions to Actions: A Theory of Planned Behaviour. In: Kuhl, J., Beckman, J. (eds.) Action-Control: From Cognition to Behaviour. Springer, Heidelberg (1985)

2. Chau, Y.K., Hu, J.H.: Information Technology Acceptance by Individual Professionals: A Model Comparison Approach. Decision Sciences 32(4), 699-719 (2001)

3. Fullan, M.: The New Meaning of Educational Change. Teachers College Press, New York (2001)

4. Hargreaves, A.: Changing Teachers, Changing Times: Teachers' Work and Culture in the Postmodern Age. Cassell, London (1994)

5. Jones, A.: A Review of the Research Literature on Barriers to the Uptake of ICT by Teachers. Becta, Coventry (2004)

6. Kennewell, S., Parkinson, J., Tanner, H.: Developing the ICT-Capable School. RoutledgeFalmer, London (2000)

7. Leithwood, K.: Understanding Successful Principal Leadership: Progress on a Broken Front. Journal of Educational Administration 43(6), 619-629 (2005)

8. Mathieson, K.: Predicting User Intentions: Comparing the Technology Acceptance Model with the Theory of Planned Behaviour. Information Systems Research 2(3), 173-191 (1991)

9. Morrison, K.: Management Theories for Educational Change. Paul Chapman, London (1998)

10. Owston, R.: Contextual Factors that Sustain Innovative Pedagogical Practice Using Technology: an International Study. Journal of Educational Change (8), 61-77 (2007)

11. Selwood, I.: Learning and Managing ICT. In: Butt, G., Gunter, H. (eds.) Modernizing Schools: People, Learning and Organizations, Continuum, London (2007)

12. Sheppard, B.: Leadership, Organizational Learning and the Successful Integration of Information and Communication Technology in Teaching and Learning. International Electronic Journal for Leadership in Learning 7(14) (2003),

http: / /www. ucalgary.ca/ iejll/

13. Taylor, S., Todd, P.: Understanding Information Technology Usage: A Test of Competing Models. Information Systems Research 5(2), 144-176 (1995)

14. Tearle, P.: ICT Implementation: What Makes the Difference? British Journal of Educational Technology 34(5), 567-583 (2003)

15. Underwood, J., Dillon, G.: Maturity Modelling: A framework for capturing the effects of technology. Technology, Pedagogy and Education 13(2), 213-224 (2004)

16. Wong, M.L., Li, C.: Is ICT a Lever for Educational Change? A Study of the Impact of ICT Implementation of Teaching and Learning in Hong Kong. Informatics in Education 5(2), 317-366 (2006)

17. Yin, R.K.: Case Study Research: Design and Methods. Sage Publications, London (2003) 